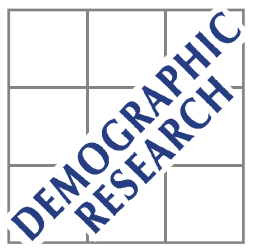

Demographic Research a free, expedited, online journal of peer-reviewed research and commentary in the population sciences published by the Max Planck Institute for Demographic Research Konrad-Zuse Str. 1, D-18057 Rostock · GERMANY www.demographic-research.org

DEMOGRAPHIC RESEARCH

VOLUME 21, ARTICLE 19, PAGES 569-598

PUBLISHED 23 OCTOBER 2009

http://www.demographic-research.org/Volumes/Vol21/19/

DOI: 10.4054/DemRes.2009.21.19

Research Article

Dissecting the compression of mortality in

Switzerland, 1876-2005

Siu Lan Karen Cheung

Jean-Marie Robine

Fred Paccaud

Alfio Marazzi

(C) 2009 Siu Lan Karen Cheung et al.

This open-access work is published under the terms of the Creative Commons Attribution NonCommercial License 2.0 Germany, which permits use, reproduction \& distribution in any medium for non-commercial purposes, provided the original author(s) and source are given credit.

See http:// creativecommons.org/licenses/by-nc/2.0/de/ 


\section{Table of Contents}

$\begin{array}{llr}1 & \text { Introduction } & 570\end{array}$

2 Background $\quad 571$

3 Data and methods $\quad 573$

$4 \quad$ Results $\quad 575$

$5 \quad$ Summary and discussion $\quad 582$

6 Acknowledgements $\quad 586$

$\begin{array}{ll}\text { References } & 587\end{array}$

Appendix 593 


\title{
Dissecting the compression of mortality in Switzerland, 1876-2005
}

\author{
Siu Lan Karen Cheung 1 \\ Jean-Marie Robine ${ }^{2}$ \\ Fred Paccaud ${ }^{3}$ \\ Alfio Marazzi ${ }^{4}$
}

\begin{abstract}
This paper aims to examine changes in common longevity and variability of the adult life span, and attempts to answer whether or not the compression of mortality continues in Switzerland in the years 1876-2005. The results show that the negative relationships between the large increase in the adult modal age at death, observed at least from the 1920s, and the decrease in the standard deviation of the ages at deaths occurring above it, illustrate a significant compression of adult mortality. Typical adult longevity increased by about $10 \%$ during the last fifty years in Switzerland, and adult heterogeneity in the age at death decreased in the same proportion. This analysis has not found any evidence suggesting that we are approaching longevity limits in term of modal or even maximum life spans. It ascertains a slowdown in the reduction of adult heterogeneity in longevity, already observed in Japan and other low mortality countries.
\end{abstract}

\footnotetext{
${ }^{1}$ The University of Hong Kong. Correspondence: cslk@hku.hk. Flat 3 B, CSRP, Faculty of Social Sciences, The University of Hong Kong, 2 University Drive, Pokfulam, HKSAR. Office: +852 2241 5583, Fax: +852 2549 7161. E-mail: cslk@hku.hk.

${ }^{2}$ INSERM, Health and Demography. E-mail: robinejm@gmail.com.

${ }^{3}$ Institute for Social and Preventive Medicine, Centre Hospitalier Universitaire Vaudois and University of Lausanne. E-mail: fred.paccaud@chuv.ch.

${ }^{4}$ Institute for Social and Preventive Medicine, Centre Hospitalier Universitaire Vaudois and University of Lausanne. E-mail: alfio.marazzi@chuv.ch.
} 


\section{Introduction}

Knowing how long people can live on average, whether deaths will be compressed into a narrower band of ages as mean longevity increases, i.e. whether compression of mortality will go on, and whether there are theoretical or practical upper limits to the length of human life, is still a major concern from bio-actuarial science to public health, and a challenge for demographers.

Studies have already documented cases of compression of mortality in low mortality countries, including Switzerland, as life expectancy increases, in conjunction with the 'rectangularization of the survival curve' and with various study designs (Cheung 2001; Cheung et al. 2005b; Eakin and Witten 1995; Go et al. 1995; Hill 1993; Levy 1996; Manton and Stallard 1996; Martel and Bourbeau 2003; Nagnur 1986; Nusselder and Mackenbach 1996, 1997; Paccaud et al. 1998; Pelletier, Legare, and Bourbeau 1997; Robine 2001; Rothenberg, Lentzner, and Parker 1991; Wilmoth and Horiuchi 1999; Yashin et al. 2001). Generally, longevity is measured by life expectancy at birth $\left(\mathrm{LE}_{0}\right)$ on the population level and the maximum life span (MLS) on the individual level, but not satisfactorily because life expectancy at birth is heavily influenced by infant and premature deaths and the maximum life span is dependent on the sample size (Hayflick 2002; Manton, Stallard, and Corder 1999; Wilmoth 2000, 2002). Alternative statistical averages such as the median length of life, sometimes called the probable length of life, and the modal age at death, also called the normal age at death, are much less used to monitor longevity (Van de Walle 1982). By contrast with the small number of central indicators used, there is a wealth of indicators to measure the dispersion/variability in the age at death, such as the mean and the standard deviation, the inter-quartile range, the coefficient of variation, and the $\mathrm{C}$ family (Cheung 2003; Kannisto 2006; Robine 2001; Wilmoth and Horiuchi 1999).

In 2001, a proper method of assessing the development of the scenario of compression of mortality was proposed by Kannisto. This method essentially consists of using the adult modal age at death (M) as the central longevity indicator in combination with the standard deviation of ages at death occurring above it $(\mathrm{SD}(\mathrm{M}+))$ as a variability indicator (Kannisto 2001). Following this design compression of mortality has been thoroughly investigated in a sample of low mortality countries and regions of the world, i.e. France, Hong Kong SAR, Italy, Japan, and Sweden (Cheung 2003; Cheung and Robine 2007; Cheung, Robine, and Caselli 2008; Cheung et al. 2005a). Altogether these studies suggest that after a period of strong compression of mortality, low mortality countries may enter into a new era where the whole distribution of adult life durations is equally sliding to higher ages, best described as the shifting mortality scenario (Bongaarts 2005; Canudas-Romo 2008; Kannisto 1996), and illustrated by the latest observation in Japan (Cheung and Robine 2007). France and 
Italy seem to follow Japan with a time-lag of a few years and to be in a transitional phase between the compression and the shifting mortality scenarios, while Sweden is still boldly engaged in a phase of compression of mortality (Cheung, Robine, and Caselli 2008).

This paper aims to investigate recent changes in mean longevity and variability of the adult life span in Switzerland; to see whether the recent observations made in Japan are confirmed in a country which, although of relatively small size, has high quality mortality data, one of the highest life expectancies at birth in the world, one of the highest Centenarian Rates with one of the shortest computed Centenarian Doubling Time (Robine and Caselli 2005; Robine and Paccaud 2005), and where the occurrence of the compression of mortality has been well established (Paccaud et al. 1998). Switzerland may also carry on the compression of mortality, as does Sweden, a similarly sized country with one of the highest life expectancies at birth, or it may show an intermediate situation as do France and Italy, two of its neighboring countries.

\section{Background}

Lexis (1878) deliberated that the adult modal age at death (M) represents the most central and natural characteristic of human longevity and that deaths occurring at and above it are regarded as "normal" deaths accounting for the right-hand side of a normal distribution. Lexis theorized the idea of normal life duration, characteristic of a natural and ageing lifetime. He divided the distribution of deaths in three parts: (1) a J-curve right after birth corresponding to infant deaths; (2) the normal deaths around the late modal age at death which obey the law of accidental errors reflecting the natural lifetime; and (3) a transitional region where adult premature deaths partly overlap with normal deaths. 
Figure 1: Hypothetical symmetric distribution of ages at death around the modal age at death and 3.2 standard deviations for women, Switzerland, 1951-55

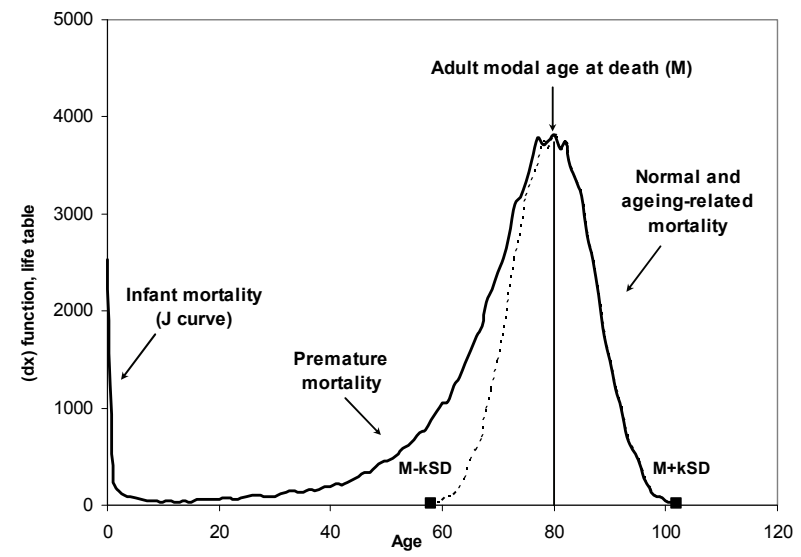

Source: Authors' calculation based on the Human Mortality Database (2007)

The Lexis approach is illustrated in Figure 1. The unfitted life table curve of deaths for women in Switzerland in 1951-55 has been treated from M, at age 80, to the tail as the upper half of the distribution of the ageing-related deaths, i.e. of normal life spans, and the lower half of this distribution has been hypothetically drawn in (a dashed line in the figure) to symmetrically mirror the upper half distribution. The premature deaths overlap the lower half of the distribution of the ageing-related deaths and lie under the main curve of deaths. Their distribution tails off at $\mathrm{M}$.

Figure 1 also illustrates a rather flat-topped and irregular pattern, which can be seen in the area of the mode. Such flatness and irregular pattern are quite frequent, not only noticed in earlier periods but also in the latest periods. For instance, in 1976-80, the numbers of deaths for women are very close to each other in the age ranges of 83 to 86 years. In 1981-85, two possible highest values are found (i.e. age 84 with 4,430 deaths and age 86 with 4,393 deaths). Similar numbers of deaths at several possible maximal points and the flatness around the modal age at death make it difficult to obtain its accurate determination without a modeling technique, taking into account the whole modal area, as highlighted by Pearson as early as 1902 .

Following the work of Lexis, some researchers proposed using the modal length of life as the best indicator of the human life span (Elderton 1903; Greenwood and Irwin 1939; Gumbel 1937). Kannisto (2001) revived the Lexis theory of normal life durations, underlying that the late modal age at death (M) and the standard deviation above it 
$(\mathrm{SD}(\mathrm{M}+))$ give a good account of old age mortality and longevity 'under a given mortality regime', definitively clarifying that $\mathrm{M}$ is not invariant and depends on the conditions of mortality of each period. It is worth noting that, according to such a definition, a normal lifetime is no longer strictly a 'biometric' quantity due to biological determinants, but one that is highly associated with the environment.

Cheung and Robine (2007) developed an associated indicator in the form of $\mathrm{M}+k \mathrm{SD}(\mathrm{M}+)$ for indicating the longest normal life duration. The Swiss data, especially the availability of a long empirical series on the maximum reported age at death (MRAD), allows for estimating $k$ with great precision. This estimation can be compared with the early observation made by Karl Pearson (1897) in 'The chance of death' - that whatever the degree of skewness of the frequency curve, practically the entirety of the frequency falls within a range of three times the standard deviation taken on either side of the mean and with the results found in the country already studied, such as Japan.

\section{Data and methods}

Age-specific death counts and population estimates made by January $1^{\text {st }}$ (Population size), downloaded from the Human Mortality Database (HMD), are grouped into five calendar years, from 1876-80 to 2001-05, to estimate the central death rates by single age and gender, according to usual demographic techniques (Calot and Sardon 2003). Standard period life tables are, then, constructed without using any modeling and closing techniques. In a life table, the $\mathrm{d}_{\mathrm{x}}$ column displays the number out of a synthetic birth cohort (usually a radix of 100,000 ) who die after attaining their $x^{\text {th }}$ birthday and before their $(x+1)^{\text {th }}$ birthday.

To estimate the mode $\left(M^{*}\right)$, a scaled normal model is fitted to the $d_{x}$ series with non-linear least square regression, from five years before the observed late modal age at death to the end of the curve (See Appendix for an example).

We computed the standard deviation above the estimated mode $\left(\mathrm{M}^{*}\right)$ with the unfitted life table $d_{x}$ series (1). The standard deviation of the individual life durations above $\mathrm{M}^{*}$ is computed under the assumption that deaths are evenly distributed within each year of age. It is the root-mean-square of the positive deviations from the mode (Kannisto 2001), i.e. the deviations of the deaths occurring between the age $\mathrm{X}=\mathrm{M}^{*}$ and $\mathrm{X}=\omega$, the last age of the life table.

$$
\mathrm{SD}\left(\mathrm{M}^{*}+\right)=\sqrt{\frac{\sum_{i=M}^{\omega}\left(X_{i}-\mathrm{M}^{*}\right)^{2}}{n}}
$$


Equation 2 shows how to obtain $k$ that accounts for how many standard deviations above the modal age at deaths $\left(\mathrm{M}^{*}\right)$ should be taken to determine the longest individual life durations. Firstly, we computed the average maximum reported age at death (AMRAD) by 5-year periods from 1876 to 2005. Then, we computed the average values for AMRAD, $\mathrm{M}^{*}$ and $\mathrm{SD}\left(\mathrm{M}^{*+}\right)$ over the whole period.

The longest life durations are indicated by $\mathrm{M}^{*+} k \mathrm{SD}\left(\mathrm{M}^{*+}\right)$, where $k$ is

$$
k=\frac{\overline{(A M R A D}-\overline{\left.M^{*}\right)}}{\overline{S D\left(M^{*}+\right)}} .
$$

The normal model gives a good fit to the life table $d_{x}$ series from five years before the observed modal age at death to the end of the curve, as shown in Figure 2, yielding a high level of R-square $\left(\mathrm{R}^{2}\right)$ between 0.995 and 0.998 . However, the fit is not perfect, especially for the highest ages as illustrated by the example given in the Appendix. The mean difference between the observed $(M)$ and the estimated mode $\left(M^{*}\right)$, over the whole period, is $+/-0.8$ years for men and $+/-0.9$ years for women, with a maximum of 2.1 years for both genders. The details of the differences are displayed in Figure A1 in the Appendix.

Figure 2: Change in the empirical life table distributions of ages at death $d(x)$ and the estimated distributions with normal fitting for men and women in Switzerland from 1876-80 to 2001-05

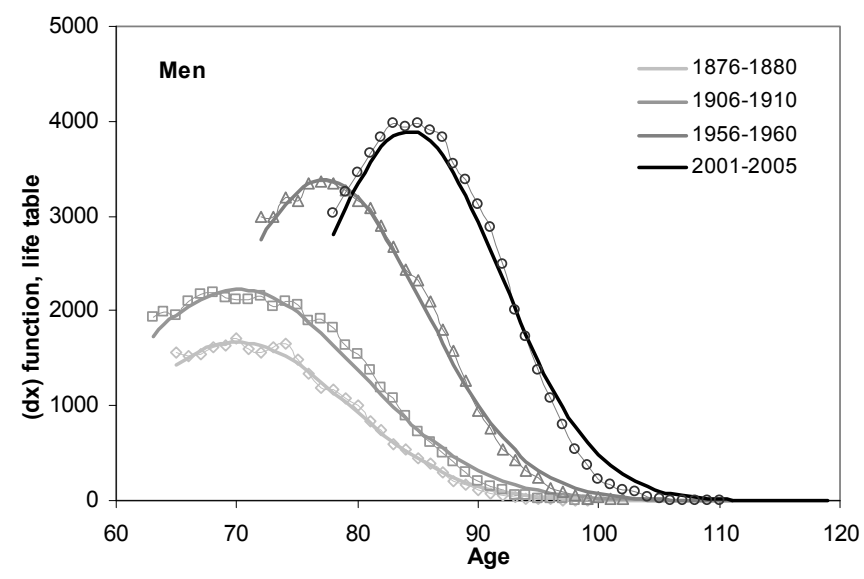


Figure 2: (Continued)

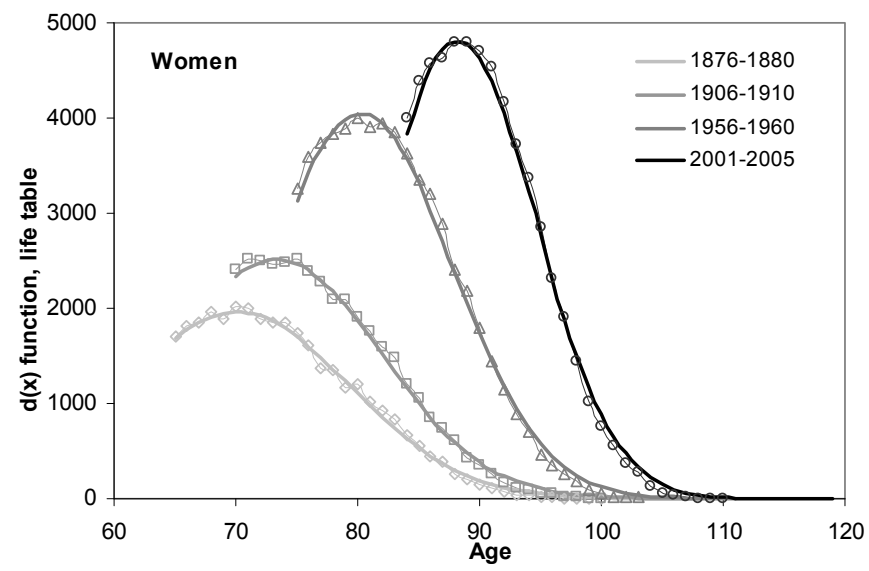

Source: Authors' calculation based on the Human Mortality Database (2007).

\section{Results}

From 1876-80 to 2001-05, life expectancy at birth $\left(\mathrm{LE}_{0}\right)$ increased in Switzerland by $97.6 \%$ for men and $96.5 \%$ for women, whereas the median life span increased respectively by $78.9 \%$ for men and $71.2 \%$ for women (see Figure 3). Except for a substantial decrease during the 5-year period 1916-1920, due to the influenza epidemics of 1918, which killed mostly young people in the 20- to 50-year age range (Robine and Paccaud 2005), $\mathrm{LE}_{0}$ and the median have been increasing monotonically to reach one of the highest values in the world today. $\mathrm{LE}_{0}$ and the median display the same chronological pattern. If 1918 is excluded, the first period ending in the 1950s is characterized by a steady rise in $\mathrm{LE}_{0}$ by four or five months per year. It is followed by a second period marked by a slower rate of increase of only three months per year. Change in the median disclosed the same two periods. 
Figure 3: Trends in the mean, $\operatorname{LE}(0)$, the median and the modal ages at death (M) for men and women in Switzerland from 1876-80 to 2001-05
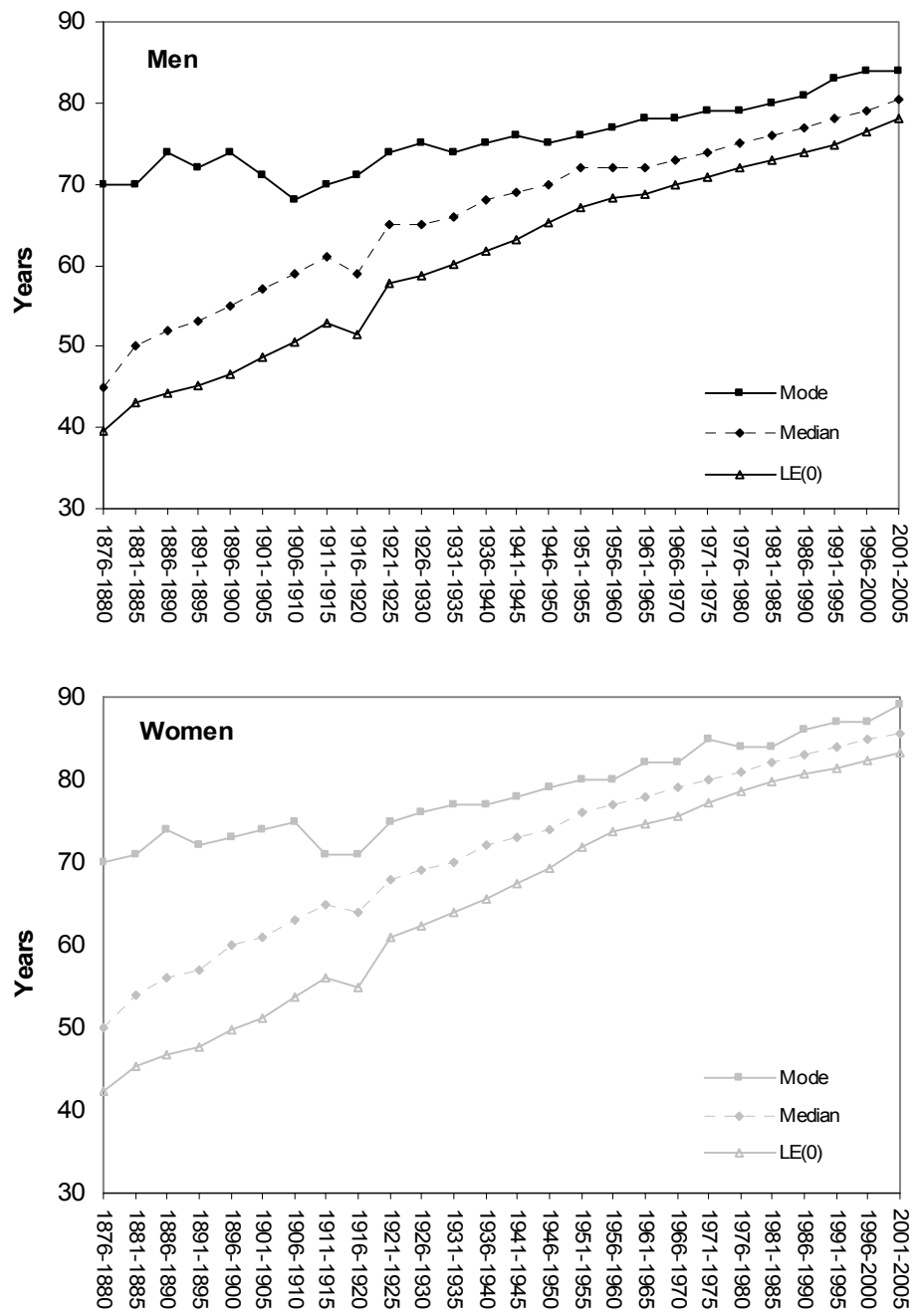

Source: Authors' calculation based on the Human Mortality Database (2007). 
However, before 1921-25, the observed modal age at deaths (M) fluctuated between 70 and 73 years, without an appreciable trend. From 1921-25 to 1946-50, a gradual rise in $\mathrm{M}$ is recorded for women from age 75 to age 79 (about two months per year) but very little for men (less than half a month per year). After the Second World War, M rose significantly for both genders. It increased by about 8 to 9 years from 1951-55 to 2001-05, from age 76 to age 84 for men and from age 80 to age 89 for women (the same two-month increase per year). The chronological changes in $\mathrm{M}$ suggest the existence of three periods characterized with different rates of increase of $\mathrm{M}$ : a first period ending around 1920 characterized by stagnation in M for both genders; a second period where $\mathrm{M}$ increased significantly only for women; and a last period after WWII where $\mathrm{M}$ increased for both genders.

Therefore, $\mathrm{LE}_{0}$ and $\mathrm{M}$ bring complementary information allowing to specify the periods of the demographic transition in Switzerland: (i) Until 1920, $\mathrm{LE}_{0}$ increased strongly while the modal age at death stagnated, leading to a substantial convergence of the central longevity indicators; (ii) from 1920 to $1950, \mathrm{LE}_{0}$ kept strongly increasing while $\mathrm{M}$ began increasing, the values still converging; and (iii) since the $1950 \mathrm{~s}, \mathrm{LE}_{0}$ increased at a slower rate while $\mathrm{M}$ kept increasing, the various values evolving henceforth in parallel. From convergence to parallel trends, the relative change between $\mathrm{LE}_{0}$ and $\mathrm{M}$ displays, firstly, a catching up of $\mathrm{LE}_{0}$ with $\mathrm{M}-$ accounting for the fall in infant mortality, then secondly a parallel shift to higher ages accounting for the fall of adult mortality. These two fundamental periods in the demographic transition are not noticeable in the pattern of change in $\mathrm{LE}_{0}$ alone. In countries where infant and child mortality is low, the adult modal age at deaths provides from then on a fair indicator of human longevity.

Changes in the estimated modal age at death $\left(\mathrm{M}^{*}\right)$ and the standard deviation of the ages at death occurring above it $\left(\mathrm{SD}\left(\mathrm{M}^{*+}\right)\right)$ are brought together in Figure 4. Before 1916-20, $\mathrm{M}^{*}$ stayed between 70 and 73 years for both genders and $\mathrm{SD}\left(\mathrm{M}^{*+}\right)$ fluctuated around 8 to 9 years, without any remarkable change over time. From 1916-20 to 2001-05, M* steadily increased by 15.2 years for women, from the age of 73 to the age of 88.2 years, and by 12.8 years for men, from the age of 71.5 to the age of 84.2 years. Decreases in $\mathrm{SD}\left(\mathrm{M}^{*+}\right)$ during the same period are much more irregular, especially for men who displayed a long period of stagnation between 1926-30 and 1976-80, about 50 calendar years. However $\mathrm{SD}\left(\mathrm{M}^{*+}\right)$ reached 7.0 and 6.2 years for men and women respectively in 2001-05. Although more steady than for men, decrease in $\operatorname{SD}\left(\mathrm{M}^{*+}\right)$ for women displays small plateaus over time. Both genders show such a plateau for the latest period, whereas $\mathrm{M}$ still follows its linear upward trend. 
Figure 4: Change in the estimated modal length of life $\left(M^{*}\right)$ and its dispersion with the unfitted life table density function for men and women in Switzerland from 1876-80 to 2001-05
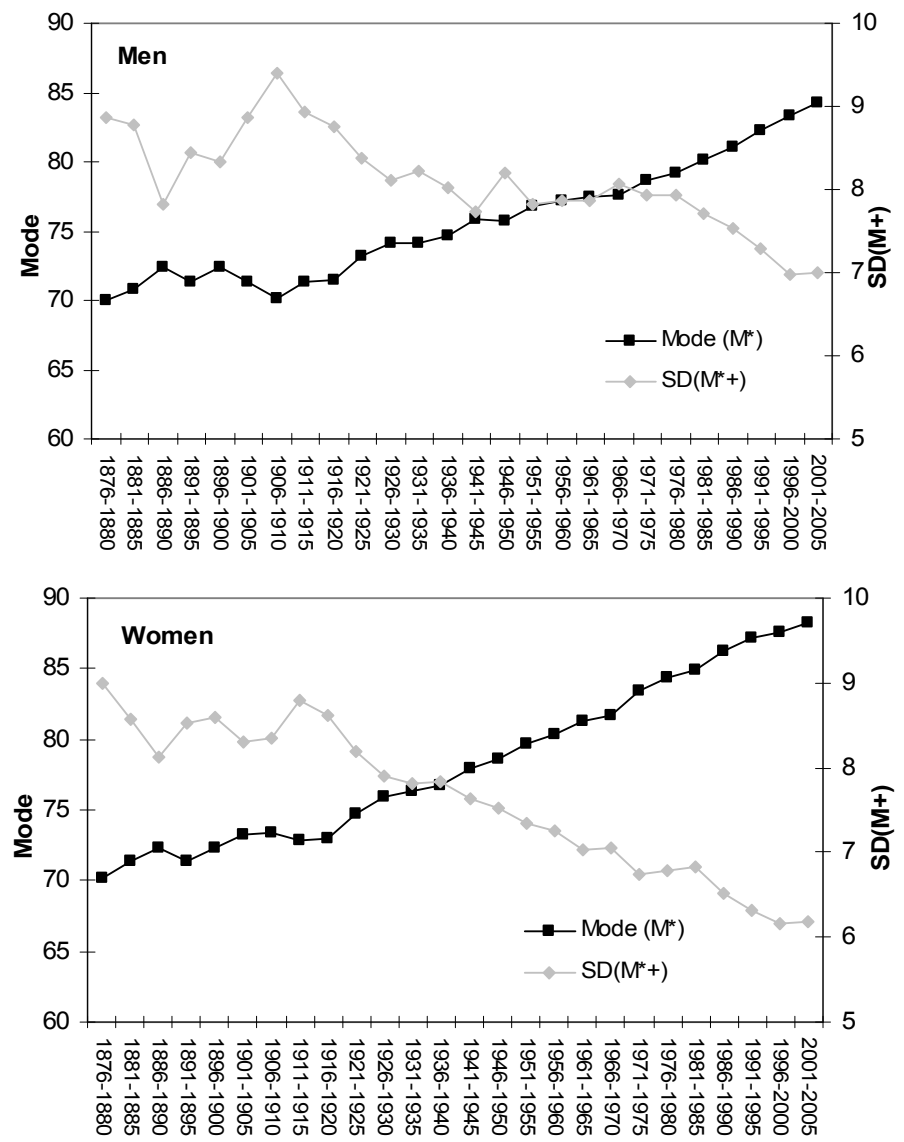

Source: Authors' calculation based on the Human Mortality Database (2007).

Sex-ratio (men divided by women values) for $\mathrm{M}^{*}$ as well as for $\mathrm{SD}\left(\mathrm{M}^{*+}\right)$ are displayed from 1876-80 to 2001-05 in Figure 5. As already noticed the differences in $\mathrm{M}^{*}$ and $\mathrm{SD}\left(\mathrm{M}^{*+}\right)$ between men and women, initially negligible, became significant during the 30 calendar years, from 1941-45 to 1971-75. Since 1971-75, both gender gaps tend to reduce slightly. By $2001-05, \mathrm{M}^{*}$ and $\mathrm{SD}\left(\mathrm{M}^{*+}\right)$ reached $95 \%$ for men and 
$113 \%$ respective of the women values, meaning that the women adult life spans are less dispersed around their higher mode than the men life spans around their lower mode.

The level of concentration of individual life durations, out of 100,000 newborn, ending in the single year of age, corresponding to the estimated modal age at death, $\mathrm{d}\left(\mathrm{M}^{*}\right)$, is indicated on the upper panel of Figure 6. For instance, for women $\mathrm{d}\left(\mathrm{M}^{*}\right)$ increased from 1,958 deaths in 1876-80 to 4,890 deaths in 2001-05. A widening gap of $\mathrm{d}\left(\mathrm{M}^{*}\right)$ between genders occurred since $1951-55$ due to a relatively slower increase in $d\left(M^{*}\right)$ for men. Before 1951-55, for both genders, $d\left(M^{*}\right)$ firmly increased over time.

The estimated proportion of deaths gathered at and above the modal age at deaths $\left(\mathrm{d}\left(\mathrm{M}^{*+}\right)\right)$ is indicated on the lower panel of Figure 6. This indicator shows the percentage of lives which end under the right-hand side of the distribution of deaths from the mode. Starting from $20 \%$ in $1876-80, \mathrm{~d}\left(\mathrm{M}^{*+}\right)$ increased asymptotically to approximately $40 \%$ in the $1950 \mathrm{~s}$. The speed of increase clearly reduced over time and, after $1951-55, \mathrm{~d}\left(\mathrm{M}^{*}+\right)$ remained at $40 \%$ for women and slightly below for men, underlining the same two periods as on the upper panel.

Figure 5: Sex-ratio (men divided by women values) for the estimated modal length of life $\left(\mathbf{M}^{*}\right)$ and its dispersion $\operatorname{SD}\left(\mathrm{M}^{*}+\right)$ in Switzerland from 1876-80 to 2001-05

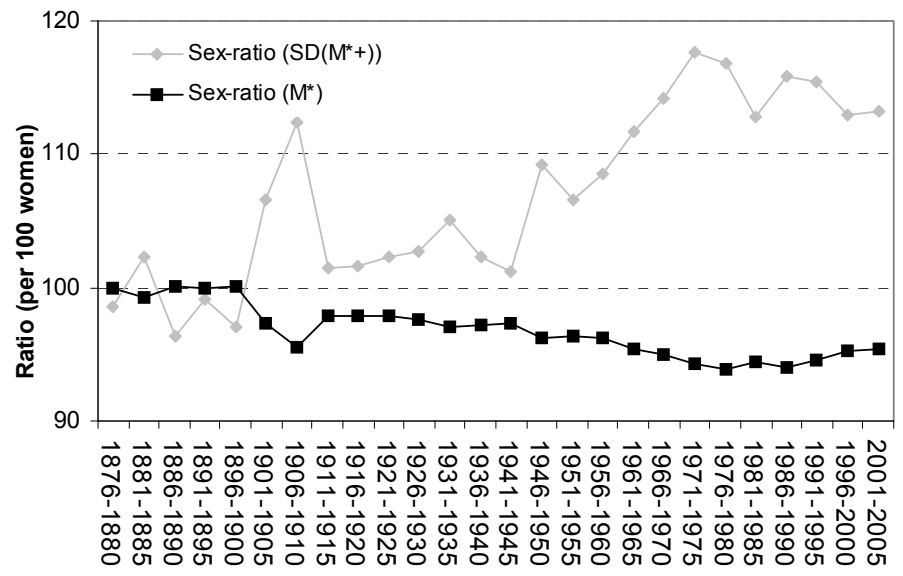

Source: Authors' calculation based on the Human Mortality Database (2007). 
Figure 6: Change in $d\left(M^{*}\right)$, the estimated number of deaths at $M^{*}$ with a normal model, and in $d\left(M^{*}+\right)$, the life table number of deaths at and above $M *$ for men and women in Switzerland from 1876-80 to 2001-05
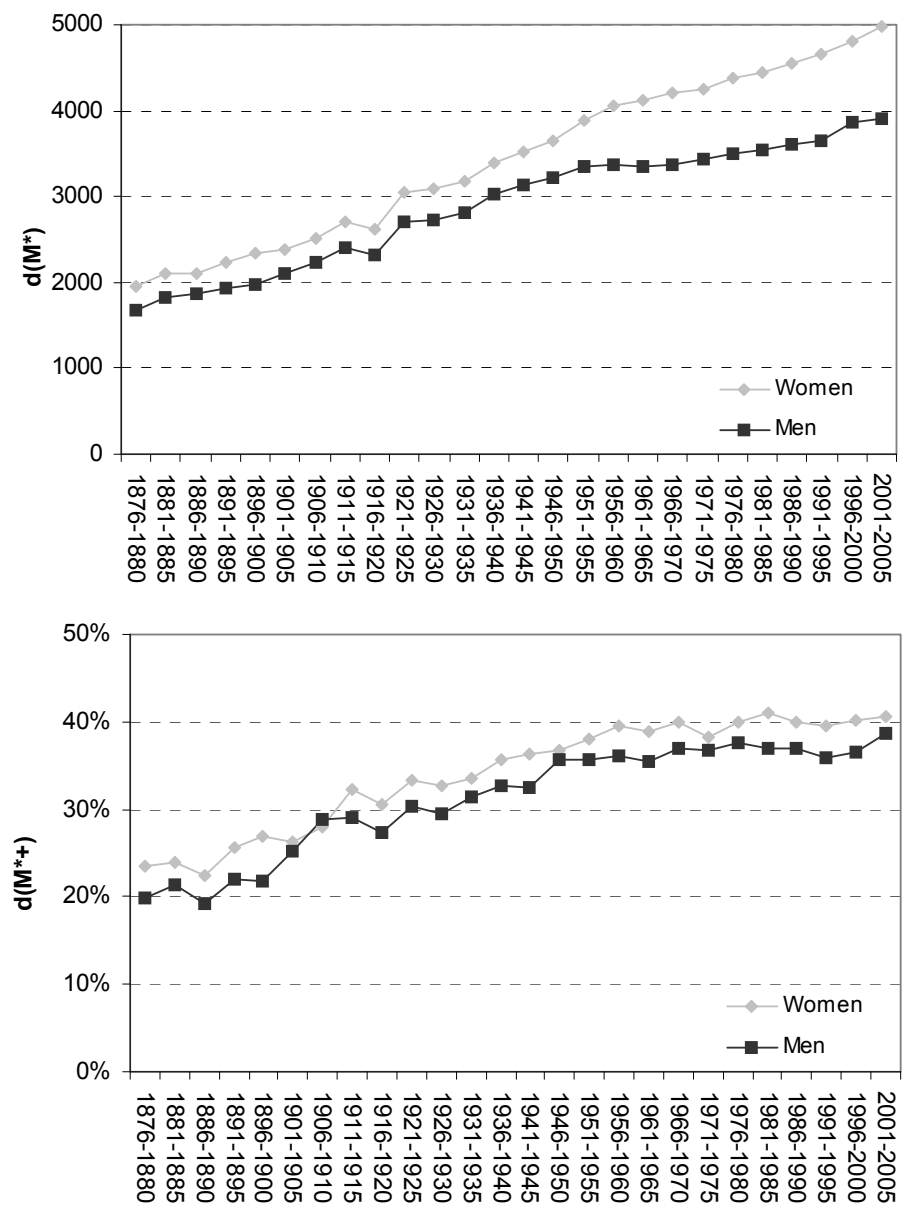

Source: Authors' calculation based on the Human Mortality Database (2007). 
Figure 7: Average maximum reported age at death (AMRAD) and $\mathrm{M}+\mathrm{kSD}(\mathrm{M}+$ ) for men and women in Switzerland from 1876-80 to 2001-05
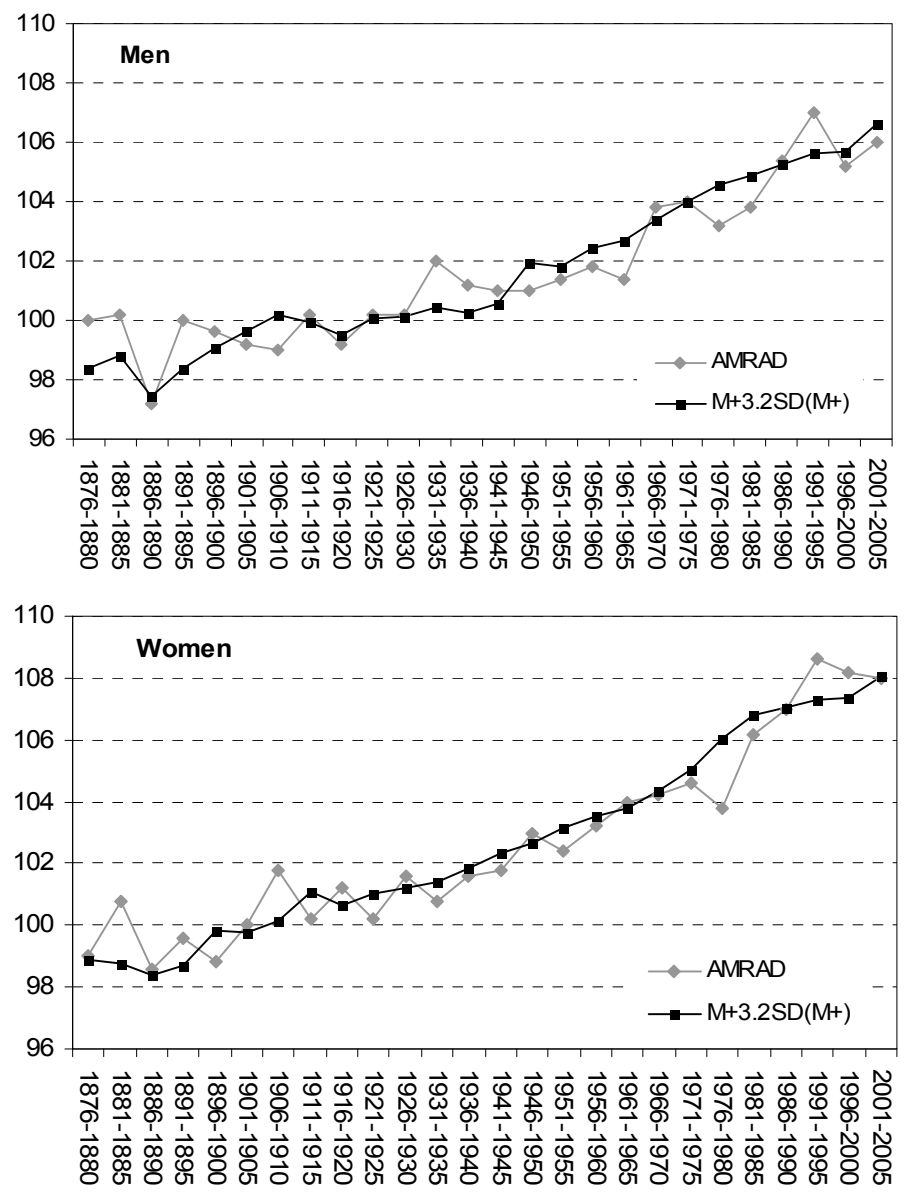

Sources: $\quad$ Authors' calculation based on the Human Mortality Database (2007), International Database on Longevity (2006) and on the data of the Swiss Federal Statistical Office. 
With an estimated value of 3.2 for $k$, Figure 7 illustrates that $\mathrm{M}+k \mathrm{SD}(\mathrm{M}+)$ provides a good estimation of the longest life durations observed in Switzerland, empirically demonstrating that the parameter $k$ can be considered constant as long as the population size remains in the same order of magnitude. $\mathrm{M}+3.2 \mathrm{SD}(\mathrm{M}+)$ follows closely, for both genders; the 5-year average maximum reported age at death (AMRAD) over time. $\mathrm{M}+3.2 \mathrm{SD}(\mathrm{M}+)$ increased by 8.2 years for men, from 98.4 years in $1876-80$ to 106.6 years in 2001-05, and by 9.1 years for women, from 98.9 years in $1876-80$ to 108 years in 2001-05.

\section{Summary and discussion}

These changes are in line with the documentation of a substantial fall in mortality among the oldest-old and a significant increase in the number of centenarians in Europe and in Japan in the last decades of the $20^{\text {th }}$ century (Robine and Paccaud 2005; Robine and Saito 2003; Robine and Vaupel 2001; Robine, Saito, and Jagger 2003, Thatcher 1999a, 2001; Vaupel and Jeune 1995; Wilmoth et al. 2000; Wilmoth and Lundström 1996), but we do not know exactly when the adult life spans started lengthening. Our analysis of the Swiss data, focusing on the adult life spans, disclosed three main periods in the demographic transition which occurred in Switzerland: (1) before 1920; (2) from the 1920s to 1950; and (3) since the 1950s.

Before 1920, the adult modal age at death (M) remained almost constant while life expectancy at birth $\left(\mathrm{LE}_{0}\right)$ firmly increased by four or five months per year. Therefore, the number of deaths gathered at $\mathrm{M}$ or above it significantly increased.

From the 1920s, the modal age at death increases (about two months per year) with some difference between genders, introducing a gender gap which widened until the 1970 s, while $\mathrm{LE}_{0}$ kept increasing by four or five months per year. For both genders, the number of deaths gathered at and above $M$ continues to firmly increase even if the modal age at death, itself, is increasing.

Since the $1950 \mathrm{~s}, \mathrm{LE}_{0}$ increases at a slower pace (about three months per year), remaining slightly stronger than the increase in the modal age at death which maintained the same pace of increase since the 1920s. The number of deaths gathered at the modal age at deaths $\left(\mathrm{d}\left(\mathrm{M}^{*}\right)\right)$ also keeps increasing but at a slower pace, and the number of deaths gathered above the modal age $\left(\mathrm{d}\left(\mathrm{M}^{*+}\right)\right)$ remained almost constant since 1956-60. The gender gaps in $\mathrm{M}^{*}$ and $\mathrm{SD}\left(\mathrm{M}^{*+}\right)$, which strongly widened during the $1940 \mathrm{~s}$ and $50 \mathrm{~s}$, continued widening in the $60 \mathrm{~s}$. But they tend to have reduced since the mid 70s.

Following Dublin (1923), life expectancy at birth $\left(\mathrm{LE}_{0}\right)$ was considered the best index of the life span and is still today the most popular longevity indicator. Averaging 
all individual life durations in a unique value as an arithmetic mean, it provided a reliable indication. Its main feature is to be highly sensitive to changes in infant and childhood mortality. This was a substantial advantage when fighting against infant mortality was a priority for public health. However, this advantage becomes less tangible and tenable when mortality chiefly attributes to an adult and elderly population. The median age at death (i.e. the age that $50 \%$ of the population can reach) provides an indication on longevity, which is a little less influenced by infant mortality, whereas the modal age at death (M) provides a fair account of the most common longevity, determined by adult mortality only (Horiuchi 2003). The differences in the trends over time of these three central longevity indicators well reflect their orientation to different aspects of mortality. However, compared to the reliability of the life expectancy at birth or the median, the modal age at death is more versatile and its right determination is crucial (Kannisto 2001; Pearson 1902).

A normal model, based on the Lexis proposal, provides a good fit of the life table $d_{x}$ series for smoothing the erratic values and allows getting a unique estimation of the modal value. Lexis applied to longevity, and more specifically to the non premature deaths, the idea of "l'homme moyen", introduced by Quetelet in 1835. In this conception, the modal age at death is not an arithmetic mean of the life durations, but a typical value along a normal curve, which expresses the deep nature of things. The modal value accounts for the central value of the frequency distribution, representing the most common individual observation, limited by minimum and maximum values following the laws of nature (Quetelet 1835, 1848, 1871). Interestingly, Switzerland was among the countries that Lexis studied when he developed his theory on the normal life span (Lexis 1877). He estimated then the normal age (i.e. the modal age at death) to be 70 years and 69.5 years for Swiss men and women, respectively, and found that $45.6 \%$ and $46.2 \%$ of the deaths, respectively for men and women, fall under the normal distribution in Switzerland. The choice of a normal distribution for summarizing human traits, such as adult height or weight, is well acknowledged today (Alter 2004). Ages at puberty or at natural menopause tend also to follow a normal distribution (Boldsen and Jeune 1990). However, several alternative models (parametric or not) can be used to get a unique estimation of the mode.

Despite the fact that strong theoretical arguments have been developed in favor of focusing on the life table death series $\left(\mathrm{d}_{\mathrm{x}}\right)$ when studying adult longevity (Barnett 1955; Benjamin 1959, 1982; Clarke 1950; Phillips 1954), demographers prefer working on the mortality series $\left(\mathrm{q}_{\mathrm{x}}\right)$, for the distribution of ages at death is the result of the mortality schedule. However, the modal age at death can be introduced in the most popular models used to describe the mortality trajectory with age, such as the Gompertz and the logistic models (Thatcher 1999b; Thatcher, Kannisto, and Vaupel 1998; Vaupel et al. 
1998). Such an introduction may contribute to reconcile the $q_{x}$ and the $d_{x}$ series approaches (Robine et al. 2006; Canudas-Romo 2008).

The negative relationships between the large increase in the adult modal age at death, observed at least from the 1920s, and the decrease in the standard deviation of the ages at deaths occurring above it, illustrate the significant compression of adult mortality which took place in Switzerland over the whole period studied. $\mathrm{M}^{*}$ increased, for instance, by $9.7 \%$ (i.e. 7.5 years) for men during the last fifty years while $\operatorname{SD}\left(\mathrm{M}^{*+}\right)$ decreased by about the same proportion, $10.6 \%$ (i.e. 0.8 year). The respective figures for women are $10.9 \%$ increase (i.e. 8.7 years) for $\mathrm{M}^{*}$ and $15.9 \%$ decrease (i.e. 1.2 years) for $\mathrm{SD}\left(\mathrm{M}^{*+}\right)$. In other words, typical adult longevity increased by about $10 \%$ during the last fifty years in Switzerland and adult heterogeneity in longevity decreased by the same proportion. This compression of adult mortality, living more similar life spans, when adult longevity is increasing, is obviously good news.

Changes in $\mathrm{M}^{*}, \operatorname{SD}\left(\mathrm{M}^{*}+\right)$, and $\mathrm{d}\left(\mathrm{M}^{*}\right)$ for five countries at the forefront of the longevity revolution - France, Italy, Japan, Sweden and Switzerland - are gathered in Table 1. Sweden apart, they all show stagnating trends for $\mathrm{SD}\left(\mathrm{M}^{*+}\right)$ since the 1990 s, whereas $\mathrm{M}^{*}$ keeps increasing. Trends in $\mathrm{SD}\left(\mathrm{M}^{*+}\right)$ were always more erratic than the trend in $\mathrm{M}^{*}$ but the synchronization in the last plateaus for 4 countries and both genders is really suggestive. James Fries proposed in 1980 a higher limit of 85 years for M and a lower limit of 4 years for SD (Fries 1980), entailing a limit value of 10,000 deaths for $\mathrm{d}(\mathrm{M})$. Current values reached by women are much higher for $\mathrm{M}$, passing 90 years for instance in Japan, still higher for $\mathrm{SD}(\mathrm{M}+), 6.2$ years for instance in Switzerland, and especially lower for $\mathrm{d}(\mathrm{M})$ with a record value of 4,980 deaths computed in Switzerland.

Japan, which displays higher adult modal age at death, shows also larger standard deviations and fewer deaths concentrated at $\mathrm{M}$. Moreover, $\mathrm{d}\left(\mathrm{M}^{*}\right)$ decreased during the last decade, showing that, in this country, increase in $M$ is no longer accompanied neither by an increase in the number of deaths occurring at $\mathrm{M}$, nor by a decrease in the variability of the ages at death above it. By contrast in France, Italy and Switzerland, $\mathrm{d}\left(\mathrm{M}^{*}\right)$ keeps increasing in the 1990s. Out of the five countries, Sweden is the only country where the compression of adult mortality is still occurring. We have no explanation for this particularity yet, although it might concern more generally the northern European countries. On the other hand, the new trend for $\operatorname{SD}\left(\mathrm{M}^{*+}\right)$ in Switzerland is based on few observations (1996-2000 and 2001-2005). Is it only a stop in the decrease or a real plateau? Only time will tell whether the compression of mortality is replaced or not, by the shifting mortality scenario (Bongaarts 2005; Canudas-Romo 2008).

If our analysis of the changes in adult ages at death in Switzerland did not find any evidence suggesting that we are approaching longevity limits in terms of modal age at death, the typical longevity, or in term of maximum life span (MLS), it confirms a 
slowdown or a stop in the reduction of adult heterogeneity in longevity, already observed in Japan and other low mortality countries. Compared to other species, longevity is extremely homogeneous in human species (Finch and Kirkwood 2000), and moreover, impressive reduction has already occurred through the demographic transition. An important question for the future is to better understand, beyond the remaining social inequalities, the limits or the potential of reduction in heterogeneity in terms of adult longevity. More than 25 years ago, Fries proposed a standard deviation of 4 years. Is it realistic from a social and/or biological point of view? Absence of research on such a topic prevents the size, the sex-ratio, and the age structures of the oldest-old segments of the population to be correctly anticipated.

Table 1: $\quad$ Estimated modal age at death $\left(\mathrm{M}^{*}\right)$, standard deviation $\left(\operatorname{SD}\left(\mathrm{M}^{*}+\right)\right.$ and number of deaths at $M^{*}$ : Fifty years of change in Switzerland compared with Japan, France, Italy and Sweden, by gender

\begin{tabular}{|c|c|c|c|c|c|c|c|}
\hline & \multicolumn{2}{|c|}{ Estimated Mode $\left(\mathbf{M}^{\star}\right)$} & \multicolumn{3}{|c|}{$\operatorname{SD}\left(M^{*}+\right)$} & \multicolumn{2}{|c|}{ Number of deaths at $\mathbf{M}^{*}$} \\
\hline & $\begin{array}{c}\text { Most } \\
\text { recent } \\
\text { values }\end{array}$ & $\begin{array}{c}\text { Change in } \\
50 \text { years } \\
\%\end{array}$ & $\begin{array}{c}\text { Most } \\
\text { recent } \\
\text { values }\end{array}$ & $\begin{array}{c}\text { Change in } \\
50 \text { years } \\
\%\end{array}$ & Recent trend & $\begin{array}{l}\text { Most } \\
\text { recent } \\
\text { values }\end{array}$ & Recent trend \\
\hline \multicolumn{8}{|l|}{ Men } \\
\hline Switzerland, 2001-2005 & 84.2 & 9.7 & 7 & -10.6 & Stagnating since $1996-2000$ & 3895 & Still increasing \\
\hline Japan 2000-2004 & 84.7 & 15.0 & 7.4 & -14.7 & Stagnating since $1990-1994$ & 3753 & Decreasing \\
\hline France, 2000 & 83.4 & 10.1 & 7.4 & -9.8 & Stagnating since 1990 & 3410 & Still increasing \\
\hline Italy, 2000 & 82.3 & 4.5 & 7.8 & 7.3 & Stagnating since 1990 & 3589 & Still increasing \\
\hline Sweden, 2000 & 84.0 & 7.4 & 6.6 & -13.5 & Still decreasing & 4053 & Still increasing \\
\hline \multicolumn{8}{|l|}{ Women } \\
\hline Switzerland, 2001-2005 & 88.3 & 10.9 & 6.2 & -15.9 & Stagnating since $1996-2000$ & 4980 & Still increasing \\
\hline Japan 2000-2004 & 90.2 & 15.6 & 6.6 & -15.9 & Stagnating since 1990-1994 & 4517 & Decreasing \\
\hline France, 2000 & 88.2 & 9.9 & 6.5 & -11.8 & Stagnating since 1990 & 4456 & Still increasing \\
\hline Italy, 2000 & 87.9 & 10.1 & 6.4 & -14.1 & Stagnating since 1990 & 4497 & Still increasing \\
\hline Sweden, 2000 & 87.8 & 10.5 & 6.2 & -16.5 & Still decreasing & 4523 & Still increasing \\
\hline
\end{tabular}

Sources: Cheung and Robine (2007) for Japan; Cheung, Robine, and Caselli (2008) for France, Italy and Sweden. 


\section{Acknowledgements}

This paper was funded by a research project on longevity with Professor Fred Paccaud, Director of the Institute for Social and Preventive Medicine, Centre Hospitalier Universitaire Vaudois and University of Lausanne when the first author was part of the INSERM research group, Health and Demography, at the University of Montpellier. An earlier version of this paper was presented at the panel Research Training Network workshop on differential mortality and causes of death that was organized by the University of Rome La Sapienza in Porto Conte-Alghero, Sardegna, Italy, and supported by the Fifth Framework Programme of the European Commission. The authors would like to thank the participants for the useful comments received. The authors are also grateful to the two anonymous reviewers for their helpful and constructive comments on the manuscript. 


\section{References}

Alter, G. (2004). Height, frailty, and the standard of living: Modelling the effects of diet and disease on declining mortality and increasing height. Population Studies 58(3): 265-279. doi:10.1080/0032472042000272339.

Barnett, H.A.R. (1955). The components of mortality. Journal of the Institute of Actuaries 81(S): 105-149.

Benjamin, B. (1959). Actuarial aspects of human lifespans. In: Wolstenholme, G.E.W. and O'Connor, M. (eds.). CIBA Foundation Colloquia on Ageing. The life span of animals. Boston: Little, Brown and Company: (5): 2-20.

Benjamin, B. (1982). The span of life. Journal of the Institute of Actuaries 109: 319-357.

Boldsen, J.L. and Jeune, B. (1990). Distribution of age at menopause in two Danish samples. Human Biology 62(2): 291-300.

Bongaarts, J. (2005). Long-range trends in adult mortality: Models and projection methods. Demography 42(1): 23-49. doi:10.1353/dem.2005.0003.

Calot, G. and Sardon, J.P. (2003). Methodology for the calculation of Eurostat's demographic indicators. ODE 3/2003/E/no 26.

Canudas-Romo, V. (2008). The modal age at death and the shifting mortality hypothesis. Demographic Research 19(3): 1179-1204. doi:10.4054/DemRes.2008.19.30.

Cheung, J. (2001). The long-term trend of non-Maori mortality and its more recent compression effect. Paper presented at the Population Association of New Zealand biannual conference, Wellington.

Cheung, S.L.K. (2003). Scalar expansion and normal longevity in Hong Kong. [PhD thesis]. Hong Kong: The Hong Kong University of Science and Technology, Division of Social Science.

Cheung, S.L.K. and Robine, J.M. (2007). Increase in common longevity and the compression of mortality: The case of Japan. Population Studies 61(1): 85-97. doi:10.1080/00324720601103833.

Cheung, S.L.K., Robine, J.M., and Caselli, G. (2008). The use of cohort and period data to analyze change in normal longevity in low mortality countries. Genus LXIV (1-2): 101-129. 
Cheung, S.L.K., Robine, J.M., Tu, J.C.E., and Caselli, G. (2005a). Change in the distribution of normal life durations through the demographic transition: The case of Hong Kong [unpublished manuscript]. INSERM/Demographie et Sante, Montpellier, France.

Cheung, S.L.K., Robine, J.M., Tu, J.C.E., and Caselli, G. (2005b). Three dimension of the survival curve: Horizontalization, verticalization, and longevity extension. Demography 42(2): 243-258. doi:10.1353/dem.2005.0012.

Clarke, R.D. (1950). A bio-actuarial approach to forecasting rates of mortality. Proceedings of the Centenary Assembly of the Institute of Actuaries II: 12-27.

Dublin, L.I. (1923). The possibility of extending human life. Metron III (2): 175-197.

Eakin, T. and Witten, M. (1995). How square is the survival curve of a given species? Experimental Gerontology 30: 33-64. doi:10.1016/0531-5565(94)00042-2.

Elderton, W.P. (1903). Graduation and analysis of a sickness table. Biometrika 2(3): 260-272. doi:10.1093/biomet/2.3.260.

Finch, C.E. and Kirkwood, T.B.L. (2000). Chance, development, and aging. Oxford University Press.

Fries, J.F. (1980). Aging, natural death, and the compression of morbidity. The New England Journal of Medicine 303(3): 130-135.

Go, C.G., Brustrom, J.E., Lynch, M.F., and Aldwin, C.M. (1995). Ethnic trends in survival curves and mortality. The Gerontologist 35(3): 318-326.

Greenwood, M. and Irwin, J.O. (1939). The biostatistics of senility. Human Biology 11(1): 1-23.

Gumbel, E.J. (1937). La Durée extrême de la vie humaine. Actualités Scientifiques et Industrielles. Herman et Cie, Editeurs. Paris.

Hayflick, L. (2002). Anarchy in gerontological terminology. The Gerontologist 42(3): 416-421.

Hill, G.B. (1993). The entropy of the survival curve: An alternative measure. Canadian Studies in Population 20(1): 43-57.

Horiuchi, S. (2003). Interspecies differences in the life span distribution: humans versus invertebrates. In: Carey, J.R. and Tuljapurkar, S. (eds.). Population and Development Review 29(Supplement): 127-151. 
Human Mortality Database (2007). Human Mortality Database [electronic resource] University of California, Berkeley (USA), and Max Planck Institute for Demographic Research (Germany). http://www.mortality.org or www.human mortality.de (data updated on July 26, 2007).

International Database on Longevity (2006). Max Planck Institute for Demographic Research (Germany). Available at www.demogr.mpg.de/general/structure/ division1/lab-sl/90.htm

Kannisto, V. (1996). The advancing frontier of survival life tables for old age. Monographs on Population Aging, 3. Odense University Press

Kannisto, V. (2001). Mode and dispersion of the length of life. Population: An English Selection 13(1): 159-171.

Kannisto, V. (2006). Central and dispersion indicators of individual life duration: New methods. In: Robine, J.M., Crimmins, E.M., Horiuchi, S., and Zeng, Y. (eds.). Human longevity, individual life duration, and the growth of the oldest-old population. Springer Netherlands : 111-129.

Levy, M.L. (1996). La rectangularisation de la courbe des survivants. Morbidité, mortalité: Problèmes de mesure, facteurs d'evolution, essai de prospective, Aidelf n 8: 576-579.

Lexis, W. (1877). Zur Theorie der Massenerscheinungen in der menschlichen Gesellschaft. Freiburg i. B. Fr Wagner'sche Buchhandlung.

Lexis, W. (1878). Sur la durée normale de la vie humaine et sur la théorie de la stabilité des rapports statistiques. Annales de Démographie Internationale 2(5): 447-460.

Manton, K.G. and Stallard, E. (1996). Longevity in the United States: Age and sexspecific evidence on life span limits from mortality patterns 1960-1990. Journal of Gerontology: Biological Sciences 51A(5): B362-375.

Manton, K.G., Stallard, E., and Corder, L. (1999). The limits of longevity and their implications for health and mortality in developed countries. In: Health and mortality issues of global concern. Proceedings of the Symposium on Health and Mortality Brussels, 19-22 November 1997. United Nations: 324-343.

Martel, S. and Bourbeau, R. (2003). Compression de la mortalité et rectangularisation de la courbe de survie au Québec au cours du XX $\mathrm{XX}^{\mathrm{e}}$ Siècle. Cahiers Québécois de Démographie 32(1): 43-75.

Nagnur, D. (1986). Rectangularization of the survival curve and entropy: The Canadian experience 1921-1981. Canadian Studies in Population 13: 83-102. 
Nusselder, W.J. and Mackenbach, J.P. (1996). Rectangularization of the survival curve in the Netherlands, 1950-1992. The Gerontologist 36(6): 773-782.

Nusselder, W.J. and Mackenbach, J.P. (1997). Rectangularization of the survival curve in the Netherlands: An analysis of underlying causes of death. Journal of Gerontology: Social Sciences 52B(S3): 145-154.

Paccaud, F., Pinto, C.S., Marazzi, A., and Mili, J. (1998). Age at death and rectangularization of survival curve: Trends in Switzerland, 1969-1994. Journal of Epidemiology and Community Health 52: 412-415. doi:10.1136/jech.52.7.412.

Pearson, K. (1897). The chance of death. London Edward Arnold.

Pearson, K. (1902). On the modal value of an organ or character. Biometrika 1(2) 260-261.

Pelletier, F., Legare, J., and Bourbeau, R. (1997). Mortality in Quebec during the nineteenth century: From the state to the cities. Population Studies 51: 93-103. doi:10.1080/0032472031000149766.

Phillips, W. (1954). A basic curve of death. Journal of the Institute of Actuaries 80: 289-325.

Quetelet, A. (1835). Sur l'homme et le développement de ses facultés, essai d'une physique sociale. Secretary to the Royal Academy of Brussels. London: Bossange \& Co.

Quetelet, A. (1848). Du système social et des lois qui le régissent, Paris, Guillaumin, Book 1.

Quetelet, A. (1871). Anthropométrie ou mesure des différentes facultés de l'homme, Brussels, Muquardt.

Robine, J.M. (2001). Redefining the stages of the epidemiological transition by a study of the dispersion of life spans: The case of France. Population 13(1): 173-194.

Robine, J.M. and Paccaud, F. (2005). Nonagenarians and centenarians in Switzerland, 1860-2001: A demographic analysis. Journal of Epidemiology and Community Health 59: 31-37. doi:10.1136/jech.2003.018663.

Robine, J.M. and Caselli, G. (2005) An unprecedented increase in the number of centenarians. Genus LXI(1): 57-82. 
Robine, J.M. and Vaupel, J.W. (2001). Supercentenarians: Slower ageing individuals or senile elderly? Experimental Gerontology 36: 915-930. doi:10.1016/S05315565(00)00250-3.

Robine, J.M. and Saito, Y. (2003). Survival beyond age 100: Acceleration of the evolutions in Japan. Population and Development Review 29: 208-228.

Robine, J.M., Cheung S.L.K., Thatcher, A.R., and Horiuchi, S. (2006). What can be learnt by studying the adult modal age at death? PAA paper, Population Association of America Annual Meeting, Los Angeles, California. U.S.A. March 30 - April 1, 2006.

Robine, J.M., Saito, Y., and Jagger, C. (2003). The emergence of extremely old people: the case of Japan. Experimental Gerontology 37(7): 739-743.

Rothenberg, R., Lentzner, H.R., and Parker, R.A. (1991). Population aging patterns: The expansion of mortality. Journal of Gerontology: Social Science 46(S2): 6670.

Thatcher, A.R. (1999a). The demography of centenarians in England and Wales. Population Trends 162 (1): 5-43.

Thatcher, A.R. (1999b). The long-term pattern of adult mortality and the highest attained age. Journal of Royal Statistic Society 162, 5-43. doi:10.1111/1467985X.00119.

Thatcher, A.R. (2001). The demography of centenarians in England and Wales. Population 13(1): 139-156.

Thatcher, A.R., Kannisto, V., and Vaupel, J. W. (1998). The force of mortality at ages 80 to 120 . Odense: Odense University press.

Van de Walle, E. (1982). Multilingual Demographic Dictionary. International Union for the Scientific Study of Population. Ordina Editions. Belgium.

Vaupel, J.W. and Jeune, B. (1995). The emergence and proliferation of centenarians. In: Jeune, B and Vaupel, J.W. (eds.). Exceptional longevity: From prehistory to the present, Denmark: Odense University Press: 109-16.

Vaupel, J.W., Carey, J.R., Christensen, K., Johnson, T.E., Yashin, A.I., Holm, N.V., Iachine, I.A., Kannisto, V., Khazaeli, A.A., Liedo, P., Longo, V.D., Zeng, Y., Manton, K.G., and Curtsinger, J.W. (1998). Biodemographic trajectories of longevity. Science 280: 855-860. doi:10.1126/science.280.5365.855. 
Wilmoth, J.R. (2000). Demography of longevity: Past, present, and future trends. Experimental Gerontology 35(9-10): 1111-1129. doi:10.1016/S05315565(00)00194-7.

Wilmoth, J.R. (2002). Human longevity in historical perspective. In: Timiras, P.S. (ed.). Physiological Basis of Aging and Geriatrics, $3^{\text {rd }}$ edition, Boca Raton, FL: CRC Press: 11-24.

Wilmoth, J.R., Deegan, L.J., Lundström, H., and Horiuchi, S. (2000). Increase of maximum life-span in Sweden, 1861-1999. Science: 2366-2368. doi:10.1126/science.289.5488.2366.

Wilmoth, J.R. and Horiuchi, S. (1999). Rectangularization revisited: Variability of age at death within human populations. Demography 36(4): 475-495. doi: $10.2307 / 2648085$.

Wilmoth, J.R. and Lundström, H. (1996). Extreme longevity in five countries: Presentation of trends with special attention to issues of data quality. European Journal of Population 12: 63-93. doi:10.1007/BF01797166.

Yashin, A.I., Begun, A.S., Boiko, S.I., Ukraintseva, S.V., and Oeppen, J. (2001). The new trends in survival improvement require a revision of traditional gerontological concepts. Experimental Gerontology 37: 157-167. doi:10.1016/S0531-5565(01)00154-1. 


\section{Appendix}

This appendix includes an example of the normal fitting of the life table $d_{x}$ series (Tables A1 and A2) and displays the differences between $M$ and $M^{*}$ for each 5-year period (Figure A1).

1) To fit a normal distribution to the $d_{x}$ series around and above the observed modal age at death, it is necessary to encompass the vicinity of the mode (Pearson 1902). But how many points before the mode (M) should be included? Figure 1 illustrates an irregular pattern, which can be seen in the area of the mode. It also shows that premature mortality will distort the distribution if too many years before $\mathrm{M}$ are included. A previous study, including sensitivity analysis, showed that five years is a good compromise fitting most of the historical situations observed in Europe (Cheung, Robine, and Caselli 2008).

Table A1 provides observed and fitted $\mathrm{d}_{\mathrm{x}}$ values according to a normal model (A1), starting five years before $\mathrm{M}$, for the male life table under the Swiss mortality conditions of 1876-80. Table A2 displays the parameters of equation A1.

$$
y=a e^{\left[-0.5\left(\frac{\left(x-x_{0}\right)}{b}\right)^{2}\right]}
$$

For the period 1876-80, with a mode (M) observed at age 70 (see Table A1, column 1), the normal modal age at death $\left(\mathrm{M}^{*}\right)$ for men is estimated to be located at 70.04 years (see Table A2). Column 2 of Table A1 gives the corresponding normal $d_{x}$ series. As the total number of deaths in the 1876-80 life table starting from five years before the observed mode $(27,838$ deaths) is slightly smaller than the total of deaths estimated by the normal model $(28,116)$, a scaled normal $\mathrm{d}_{\mathrm{x}}$ series is produced (column 3) by multiplying the normal series by the ratio of the two totals (i.e. 0.990). This adjustment has no impact on the modal values $\left(\mathrm{M}^{*}\right.$ and $\mathrm{SD}\left(\mathrm{M}^{*+}\right)$ but avoids the number of deaths at $\mathrm{M}^{*}, \mathrm{~d}\left(\mathrm{M}^{*}\right)$, to be overestimated.

2) Differences between $M$ and $M^{*}$ for each 5-year period of the study. 
Table A1: Distribution of the ages at death ( $d_{x}$ life table series), starting five years before the observed mode (M), according to the 1876-80 Swiss mortality conditions for men: [1] observed, [2] normal, and [3] scaled normal $d_{x}$ series

\begin{tabular}{|c|c|c|c|c|}
\hline Age & $\begin{array}{c}\text { Observed } \\
\mathrm{d}_{\mathrm{x}} \text { series }\end{array}$ & $\begin{array}{l}\text { Normal } \\
\mathrm{d}_{\mathrm{x}} \text { series }\end{array}$ & $\begin{array}{c}\text { Scaled } \\
\text { normal } \\
\mathrm{d}_{\mathrm{x}} \text { series }\end{array}$ & $\begin{array}{c}{[3]-[1]} \\
\text { Differences } \\
\text { betw een } \\
\text { scaled normal } \\
\text { and observed } \\
\text { deaths } \\
\end{array}$ \\
\hline 65 & 1570 & 1448 & 1434 & -136 \\
\hline 66 & 1528 & 1529 & 1514 & -14 \\
\hline 67 & 1548 & 1595 & 1580 & 32 \\
\hline 68 & 1618 & 1645 & 1628 & 10 \\
\hline 69 & 1630 & 1675 & 1659 & 29 \\
\hline 70 & 1712 & 1686 & 1670 & -42 \\
\hline 71 & 1598 & 1677 & 1660 & 62 \\
\hline 72 & 1570 & 1648 & 1632 & 62 \\
\hline 73 & 1621 & 1600 & 1584 & -37 \\
\hline 74 & 1645 & 1535 & 1520 & -125 \\
\hline 75 & 1491 & 1455 & 1441 & -50 \\
\hline 76 & 1340 & 1363 & 1350 & 10 \\
\hline 77 & 1182 & 1262 & 1249 & 67 \\
\hline 78 & 1170 & 1154 & 1143 & -28 \\
\hline 79 & 1071 & 1043 & 1032 & -38 \\
\hline 80 & 1012 & 931 & 922 & -90 \\
\hline 81 & 841 & 821 & 813 & -28 \\
\hline 82 & 752 & 716 & 709 & -43 \\
\hline 83 & 590 & 617 & 611 & 21 \\
\hline 84 & 531 & 525 & 520 & -11 \\
\hline 85 & 443 & 441 & 437 & -6 \\
\hline 86 & 382 & 367 & 363 & -18 \\
\hline 87 & 288 & 301 & 298 & 10 \\
\hline
\end{tabular}


Table A1: (Continued)

\begin{tabular}{|c|c|c|c|c|}
\hline Age & $\begin{array}{c}\text { Observed } \\
\mathrm{d}_{\mathrm{x}} \text { series } \\
\end{array}$ & $\begin{array}{l}\text { Normal } \\
\mathrm{d}_{\mathrm{x}} \text { series }\end{array}$ & $\begin{array}{c}\text { Scaled } \\
\text { normal } \\
\mathrm{d}_{\mathrm{x}} \text { series } \\
\end{array}$ & $\begin{array}{c}{[3]-[1]} \\
\text { Differences } \\
\text { between } \\
\text { scaled normal } \\
\text { and observed } \\
\text { deaths } \\
\end{array}$ \\
\hline 88 & 207 & 244 & 242 & 35 \\
\hline 89 & 162 & 196 & 194 & 31 \\
\hline 90 & 118 & 155 & 154 & 35 \\
\hline 91 & 78 & 121 & 120 & 43 \\
\hline 92 & 51 & 94 & 93 & 42 \\
\hline 93 & 33 & 72 & 71 & 38 \\
\hline 94 & 22 & 54 & 54 & 31 \\
\hline 95 & 12 & 40 & 40 & 28 \\
\hline 96 & 12 & 30 & 29 & 17 \\
\hline 97 & 4 & 22 & 21 & 17 \\
\hline 98 & 3 & 16 & 15 & 13 \\
\hline 99 & 1 & 11 & 11 & 10 \\
\hline 100 & & 8 & 8 & 8 \\
\hline 101 & & 5 & 5 & 5 \\
\hline 102 & & 4 & 4 & 4 \\
\hline 103 & & 3 & 2 & 2 \\
\hline 104 & & 2 & 2 & 2 \\
\hline 105 & & 1 & 1 & 1 \\
\hline 106 & & 1 & 1 & 1 \\
\hline Total deaths & 27838 & 28116 & 27838 & \\
\hline Modal age (years) & 70 & 70.04 & 70.04 & \\
\hline $\mathbf{d}(\mathbf{M})$ & 1712 & 1686 & 1670 & \\
\hline
\end{tabular}


Table A2: Parameters of the normal model, starting five years before the observed $M$, under the 1876-80 Swiss mortality conditions for men

\begin{tabular}{llll}
\hline & Coefficient & Std Error & P Value \\
\hline & & & \\
a & 1686 & 15.6806 & $<0.0001$ \\
b & 9.136 & 0.1931 & $<0.0001$ \\
x0 & 70.0423 & 0.2108 & $<0.0001$ \\
\hline
\end{tabular}

Figure A1: Differences between the observed $(M)$ and the estimated ( $\left.M^{*}\right)$ modal length of life for men and women in Switzerland from 1876-80 to 2001-05

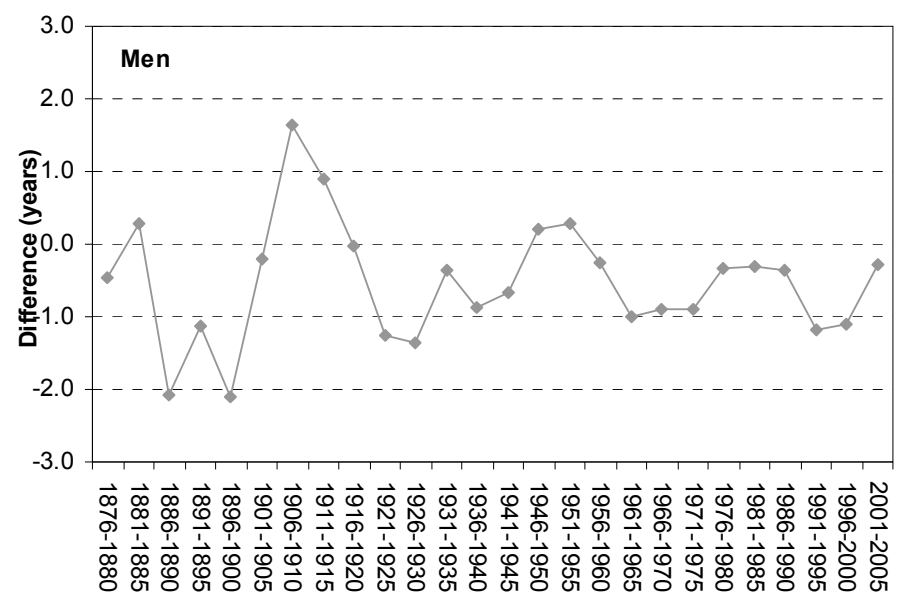




\section{Figure A1: (Continued)}

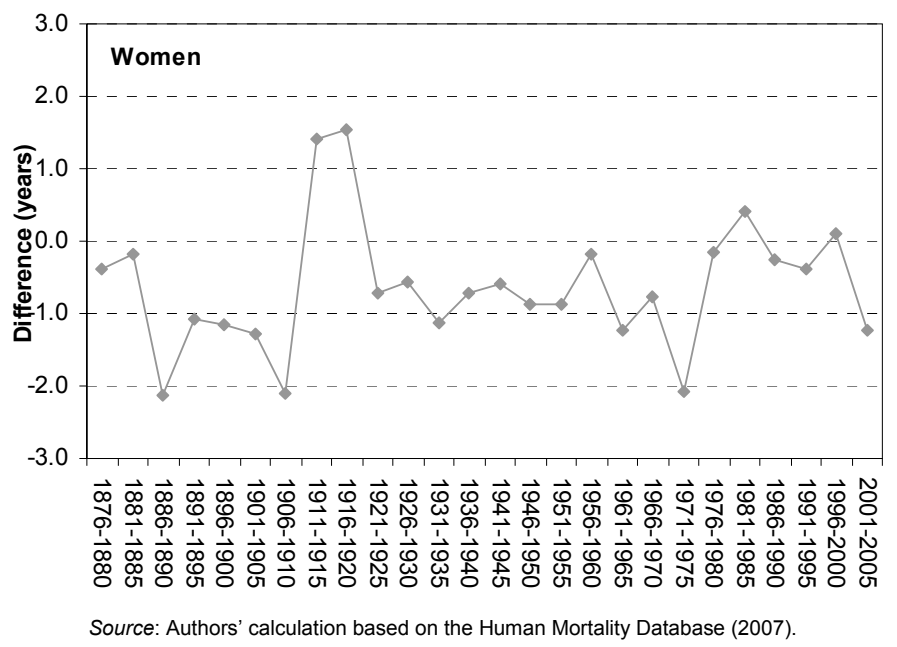


Cheung et al.: Dissecting the compression of mortality 